\title{
Risas y sonrisas del profesorado. Percepciones de estudiantes de la Universidad Veracruzana*
}

\author{
Griselda Hernández Méndez ${ }^{1}$ \\ (D) $h t t p: / / o r c i d . o r g / 0000-0002-8367-6465$ \\ Universidad Veracruzana, México
}

DOI: http://dx.doi.org/10.17081/eduhum.19.32.2531

Recibido: 05 de junio de 2016

Aceptado: 03 de septiembre de 2016

\section{Teachers' laughs and smiles. Perceptions of students from Universidad Veracruzana}

Palabras clave:

Paralingüística, Percepción,

Efectividad de la enseñanza,

Risas y sonrisas.

Keywords:

Paralinguistic, Perception, Teaching effectiveness, Laughs and smiles.

\begin{abstract}
Resumen
Este artículo es resultado de una investigación, cuyo objetivo consistió en analizar la relación entre la percepción de los estudiantes respecto a los aspectos personales de los profesores como edad, género y elementos de comunicación no verbal (proxémica, kinésica, paralingüística y apariencia física) y la efectividad de la enseñanza. En este texto se dan a conocer los resultados referidos a los elementos no verbales paralingüísticos y, en específico, las risas y sonrisas docentes. Se trabajó a partir del método hermenéutico, siguiendo algunas pautas de la etnografía, como la técnica de la entrevista a profundidad. Los resultados muestran que la presencia (con las diversas maneras de reír) o ausencia de risas y sonrisas de los profesores afectan positiva o negativamente la relación entre los profesores y los estudiantes y, por ende, el proceso de enseñanza-aprendizaje.
\end{abstract}

\begin{abstract}
This research paper aims to analyze the partial results corresponding to the relationship between students' perception in relation with some teachers' personal issues such as age, gender and non-verbal communication (proxemics, kinesics, paralinguistics, and physical appearance). These results make it possible to know all the data related to teachers' non-verbal elements, paralanguage, smiles and laughs. This study was conducted based on hermeneutic method and follows guidelines related to ethnography, such as in depth interview study. In a similar manner, the results show how the presence and absence of teachers' laughs and smiles may positively or negatively affect the teachers-students relationship, as well the learning-teaching process.
\end{abstract}

\section{(c) $(9)$}

Referencia de este artículo (APA): Hernández, G. (2017). Risas y sonrisas del profesorado. Percepciones de estudiantes de la Universidad Veracruzana. En Revista Educación y Humanismo, 19(32), 53-66. http://dx.doi.org/10.17081/eduhum.19.32.2531

\footnotetext{
* Artículo resultado en la línea de investigación "La efectividad de enseñanza y su relación con los rasgos personales del profesorado. Percepciones de los estudiantes”. Financiación Universidad Veracruzana.

1. Doctora en Filosofía y en Ciencias de la Educación. Docente Investigadora de la Universidad Veracruzana, México. griseldahm2001@yahoo.com.mx
} 


\section{Introducción}

El estudio del lenguaje no verbal resulta complejo e incluso osado, justamente por el dilema que reside en saber con precisión si lo que tradicionalmente se entiende como no verbal, en realidad lo sea. De allí la sugerencia de analizar lo no verbal conjuntamente con lo verbal en tanto unidades indivisibles (Hernández, 2011). Consciente de ello, la autora de este trabajo se adentra solícitamente en el análisis de los mensajes que no vienen acompañados de palabras, a los que se denomina como "no verbales", y que los profesores manifiestan en el aula escolar: miradas, sexo, edad, atuendos, risas, entre otros, dado que todo ello constituye parte del lenguaje no verbal que los profesores emplean consciente e inconscientemente para comunicarse.

El presente artículo es producto de una investigación cuyo objetivo fue analizar las implicaciones de lo kinésico, lo proxémico, la paralingüística y la apariencia física del profesorado en la efectividad de la enseñanza, y en específico en las relaciones interpersonales. Por la amplitud y profundidad temática, para efectos de este texto, solo daremos a conocer algunos resultados referidos a los fenómenos paralingüísticos, y siendo estos aun así tan vastos, nos limitaremos a revisar exclusivamente las risas y sonrisas del profesorado en las aulas y su relación con la efectividad de la enseñanza, desde las percepciones de los estudiantes universitarios. Es necesario aclarar que la sonrisa, a diferencia de la risa, forma parte de los signos kinésicos, en tanto se trata de un gesto del rostro; mientras que la risa es un signo paralingüístico diferenciador. Para este estudio, no se hicieron distinciones al respecto porque se analizan conjuntamente, aunque se resalta el efecto paralingüístico.

El objetivo particular del artículo es, por tanto, generar la reflexión en torno a la relevancia que tienen la presencia y ausencia de las risas y sonrisas en la relación entre estudiantes y profesores, y específicamente en el proceso de enseñanza-aprendizaje.

El texto se divide en tres apartados: el primero presenta grosso modo la metodología de indagación; en el segundo, se revisa el concepto de percepción, ya que el estudio busca recoger las percepciones de estudiantes sobre las risas y sonrisas de sus profesores; y en el tercer apartado, se analizan las distintas percepciones de los alumnos entretejiéndolas con la teoría.

Los sustentos de la investigación general se encuentran en varios enfoques teóricos:

- La explicitación de la noción de práctica docente como un todo complejo, multidimensional (dimensiones imbricadas, superpuestas y determinantes, como lo social, institucional, valoral, pedagógico, interpersonal y personal) y multirreferencial (Fierro \& Fortoul, 1999; Hernández, 2011).

- La noción de percepción, que es explicada desde la teoría psicológica y la sociológica (principalmente se retoma la concepción de habitus de Bourdieu), puesto que la percepción depende de la persona que percibe y del lugar, momento y medio del perceptor. 
- Por último, para sustentar las interpretaciones concernientes al lenguaje no verbal, se recurrió a una diversidad de autores, sin perder el sentido y la coherencia de la investigación, en especial de Birdwhistell (1966), Knapp (1999), Davis (2000) y Poyatos (1994). Todos ellos constituyen las bases para innumerables teóricos recientes en el tópico de lo no verbal. Se prefirió ir lo más directamente a las fuentes, puesto que los textos recientes son reproducciones de estos.

\section{Método}

El paradigma que subyace a la indagación es el hermenéutico, puesto que "la hermenéutica [...] utiliza un proceso interpretativo más personal en orden a «comprender la realidad»" (Ruiz, 2003, pp.12-13).

En este caso, se concibe la hermenéutica como una vía mediante la cual se recaba la información, y como un filtro por el que se hacen interpretaciones. El hermeneuta interpreta todos estos sucesos inmediatos a la luz de experiencias y sucesos anteriores, así como de cualquier elemento que ayude a entender mejor la situación estudiada (Ruiz, 2003, p.13).

En la investigación se toma en cuenta la mirada del hermeneuta desde una perspectiva étic, y la de los informantes, desde la perspectiva emic. Ambas perspectivas son complementarias y convergentes en el proceder metodológico. La orientación étic o ética guarda relación con los datos que formula la hermeneuta, tomando en cuenta el conocimiento construido, transcultural; mientras que lo emic o émica va en función de los modelos o patrones que prevalecen en una cultura concreta e individual (Ruiz, 2003). De allí la necesidad de la mirada holística, del análisis de la situación como un todo y no solo como una parte. En el entendimiento de que si bien para efectos del presente artículo, nos concentramos en un aspecto muy específico (para profundizar), en la investigación, todos esos elementos se ven como partes de un todo.

Metodológicamente, se procedió según algunas pautas propias de la etnografía, como la técnica de la entrevista a profundidad, con el apoyo del guion de entrevista semiestructurada, para que el informante nos relatara sus percepciones. El guion es extenso porque en la investigación general se analizaron varios aspectos del lenguaje no verbal de los profesores y su incidencia en la efectividad de la enseñanza. Sin embargo, para la elaboración de este artículo, se recuperan solo tres preguntas de las que se plantearon a los alumnos entrevistados: 1 . ¿Cómo percibes a los maestros que no ríen o poco lo hacen y cómo percibes a los que sí lo hacen?, 2. ¿Qué expresan los maestros con su sonrisas y risas? y, 3. ¿Qué risas y sonrisas de tus profesores te agradaron y cuáles no?, menciona las razones.

Precisamos, además, que la información es amplia y de gran riqueza en sus especificaciones, más en este artículo solo se dan a conocer algunas percepciones de los alumnos de dos facultades: Pedagogía e Idiomas, ambas de la Universidad Veracruzana. 


\section{Proceso de selección de la muestra}

Aunque en los estudios con enfoque cualitativo no son indispensables los muestreos; para la organización y procesamiento de datos, se prefirió seleccionar primero las facultades $\mathrm{y}$, posteriormente, se hizo un recorte de los estudiantes que participarían como informantes claves. De esta manera, en este artículo, se presentan los resultados de dos facultades (elegidas aleatoriamente), que intervinieron en la investigación: la Facultad de Idiomas y la de Pedagogía de la Universidad Veracruzana, en la ciudad de Xalapa, Veracruz.

Para la selección de los estudiantes, se utilizó un procedimiento intencional, procurando que participaran hombres y mujeres; de promedios altos, regulares y bajos; que cursaran, además, el último semestre, y que estuvieran interesados en participar. Sus respuestas fueron transcritas tal cual, conservando su anonimato a través de la asignación de un número, así por ejemplo, al estudiante número uno de Pedagogía se le refiere como Est. 1 Ped, y al de Idiomas, también número uno, como Est. 1 Idio, y así sucesivamente. En total, fueron veinte entrevistas, diez para cada Facultad. Después de una mesurada revisión de todas las respuestas de los entrevistados, se eligieron los estratos o "voces de los alumnos" que más impacto tienen por el fondo de su respuesta, esto es, que denotan la relevancia de las risas y sonrisas de los profesores, sobre todo en la relación maestro-alumno.

Para atender el anonimato, tampoco se indican los nombres de los maestros aludidos por los entrevistados. A estos últimos se les asignan letras iniciales fortuitas, verbigracia, Maestra M.

\section{Noción de percepción}

De acuerdo con Gage (en Hernández, 2011), la efectividad de la enseñanza depende de quien perciba. En ese sentido, para muchos alumnos, las risas son necesarias e incidentes en la efectividad de la enseñanza, y para otros son innecesarias e intrascendentales. De ese modo, el concepto de percepción debe analizarse a partir de dos miradas, lo psicológico y lo social, en tanto el alumno-perceptor es un ser individual y social al mismo tiempo. Desde el punto de vista psicológico, la percepción se define como:

El proceso de extracción de información o acumulación de la información usando los cinco sentidos fisiológicos: vista, oído, tacto, gusto y olfato. Transciende a la sensación en la medida en que la integra dándole significado y organización; es decir, interpreta, analiza y organiza los estímulos. De ahí que no solo implica las actividades de los órganos sensoriales, sino también las del cerebro. (Feldman, en Hernández, 2011, p.46)

La percepción es influenciada por procesos subjetivos del que percibe; por sus emociones, deseos, intenciones, gustos e incluso sentimientos. De allí que para Mann (1972) la percepción es de carácter interpersonal; puesto que al percibir a los otros, de alguna manera se evalúa, juzga o crítica a partir de procesos subje- 
tivos, que llegan a constituirse en creencias. Lo interesante de esto es que dichas creencias, que nosotros preferimos llamar percepciones, están determinadas por lo social, en tanto que el campo interpersonal es una esfera interior que otorga el campo social.

Así, la percepción tiene un fuerte sentido social. Siguiendo las ideas de Durkheim (1978), las tendencias sensibles se adaptan e inhiben a la normalidad social. Desde ese orden de ideas, las percepciones están condicionadas por lo social, verbigracia, la discriminación entre los códigos dicotómicos: belleza/fealdad, bondad/maldad, verdad/falsedad, etcétera, no la realiza el sujeto con total autonomía, pues, ello es parte de una moral social aprendida. Bourdieu (1999) nos hablaría de ethos y habitus internalizados por la vida en colectivo. Mucho podemos decir al respecto, $\mathrm{p}$ ero por efecto de espacio, cerramos este apartado comentando que las percepciones de un estudiante en torno a la enseñanza y su relación con los rasgos personales de los docentes están influenciadas por su biografía personal o historia de vida familiar, por su contexto sociocultural, por la cultura de la escuela a la que ha asistido y asiste, y por el ambiente grupal o las interacciones que se desarrollan al interior del aula escolar bajo la coordinación del maestro (Hernández, 2011).

A continuación, se examinan las percepciones de los estudiantes de las facultades de Pedagogía y de Idiomas de la Universidad Veracruzana con respecto a las risas y las sonrisas del profesorado.

\section{Resultados}

Desde 1966, Raymond Birdwhistell dedujo, a partir de sus investigaciones, que solo el $35 \%$ del mensaje humano pasa por la palabra; un $38 \%$ está vehiculado por la entonación y el resto por la actitud corporal. Por ello, concluyó que "el hombre es un ser mutisensorial que algunas veces verbaliza". Coincidentemente, Flora Davis (2000) repuso que el hombre usa las palabras cuando todo lo demás falta... Esto muestra cuán importante es el lenguaje no verbal y, dentro de este, los rasgos paralingüísticos.

Los rasgos o fenómenos paralingüísticos pueden ocurrir como modificadores de la palabra. Muchas veces funcionan como cuasi palabras (alternantes) y en otras, los diferenciadores -como reír, llorar, gritar, suspirar, jadear, bostezar, toser, carraspear, escupir, eructar, hipar y estornudar- distinguen reacciones fisiológicas y reacciones emocionales (Poyatos, en Hernández, 2011, p.128). Para este texto, nos centraremos en las risas, aunque todos tienen una peculiar relevancia dentro de lo que los profesores comunican en forma no verbal.

\section{Risas...}

La risa proyecta una enorme carga emocional y revela las personalidades. Quien ríe poco o no lo hace, puede expresar seriedad, preocupación o disgusto por su trabajo... Quien ríe mucho, generalmente, manifiesta ser una persona alegre, nerviosa, despreocupada o entusiasta. Para el entrevistado No. 1 de Pedagogía, un maestro que no ríe puede ser percibido como amargado: 
Sí, rompen con todo lo establecido. Creo que los maestros que no sonríen, se puede llegar a pensar que son amargados. (Est.1 Ped)

La amargura es una manifestación de tristeza y hasta depresión, con la que la persona se enfoca negativamente hacia el mundo-sociedad. La palabra amargura significa aflicción, sinsabor, disgusto, pesadumbre, melancolía... Tiene una fuerte relación con la efectividad de la enseñanza, porque una persona con amargura difícilmente logrará cumplir cabalmente con su tarea. Empero, el hecho de que no ría no significa necesariamente que un profesor sea amargado o frustrado, como comenta la alumna 2 de Idiomas:

Nunca reía, al contrario, siempre tenía la cara como enojada... yo interpreto que era una mujer amargada y frustrada porque no ha logrado distinguirse. (Est. 2 Idio)

Seguramente, la falta de risa más otras acciones de la maestra llevaron a la alumna 2 de Idiomas a hacer esas interpretaciones. Recordemos que lo no verbal es un elemento importante de análisis si se acompaña de lo verbal y se estudia dentro de un contexto determinado. Lo cierto es que a los estudiantes les agrada que los profesores rían. Al respecto, Stubb y Delamont (1978) encontraron en sus investigaciones con alumnos de secundaria, que a estos les gustan los maestros sonrientes, "Me gusta la profesora. A veces se ríe con nosotros" (p.34).

Los entrevistados de nuestro estudio afirmaron que les agradan las risas y sonrisas de muchos profesores, pero también les disgustan las de algunos. Veamos las primeras.

\section{Risas agradables}

Risas tiernas, simpáticas...

Como el estudio cruza los datos con las variables edad y género, muchas respuestas de los alumnos demarcan diferencias de acuerdo con la edad y el género de sus profesores, principalmente.

Las risas que más apreciaron fueron de maestras porque según ellos denotaron ternura, simpatía y confianza:

'G' siempre reía, bajito, pero siempre tenía pintada su sonrisa y era simpática y eso nos hacía confiar en ella y preguntarle cuando teníamos dudas. (Est. 1Ped)

La de la maestra ' $\mathrm{N}$ ' es una sonrisa encantadora porque se toma su tiempo para sonreír, ella daba mucha confianza... (Est.1 Ped)

A mí en particular, me fascinaban las risas de las maestras ' $\mathrm{N}$ ' y 'G'. Ellas eran muy simpáticas y transmitían gusto por la docencia, por lo que hacen... (Est.2 Ped)

La risa encierra una enorme riqueza analítica. Muchas emociones se pueden generar en los otros con una sola sonrisa. Es indicativo que las maestras percibidas como sonrientes logran generar la confianza para que los estudiantes 
se acerquen y planteen sus dudas. Esas risas les parecieron simpáticas a los estudiantes de Pedagogía. Los de Idiomas, por su parte, resaltaron la de la maestra 'M', quien no ponía una barrera entre ella y los alumnos, como lo expresa la siguiente entrevistada:

Pues, este, cómo le diré, la risa de la maestra 'M' da cierta simpatía o tal vez por su edad, no sé. Causa cierta simpatía, pero pues hay maestros que por su risa pues como que les tienes más confianza de acercarte a ellos, o sea no ponen ninguna barrera así de lleno, de que yo soy el maestro y yo nada más, -esteno puedes consultarme nada. La maestra ' $M$ ' daba confianza. (Est. 6 Idio)

Y el entrevistado 5 lo reitera:

La de la maestra ' $M$ ', por ejemplo, ella ríe mucho durante la clase, ella es... bueno a todos nos inspiran mucha ternura porque ya es mayor, eh. Consideramos que ella ha vivido muchas cosas, porque a veces nos habla de la guerra, que cuando era niña, que vivía con sus padres, que no tenía qué comer y, cosas así. Pero siempre cuando cuenta algo que sea chistoso, siempre se está riendo... El volumen de su sonrisa es alto y su risa es aguda y, siempre nos hace reír también, pero es porque su risa es como muy contagiosa y no tanto por lo que dice. (Est.5 Idio)

La maestra ' $M$ ' de Idiomas sobresale, entonces, porque ríe mucho en la clase, ella es mayor de edad y su risa es de volumen alto y agudo, además de contagiosa. Culturalmente se cree que la risa no apropiada es aquella bastante ruidosa, que según las reglas cortesanas se consideraba de mala crianza (Wildeblood \& Bryson, 1965, p.25). "El rostro, se decía en el siglo XVI, debía expresar alegría de tal modo que no se desfigurara la boca porque eso hacía parecer al riente "simple", y en el siglo XVIII la risa frecuente y alta es característica de necedad y malos modales. Y lo llaman estar alegre. Actualmente, las risas no se interpretan así, las personas tienden a reír, siendo más fácil que un alumno se acerque a un maestro sonriente que a uno serio" (Hernández, 2011, p.130) y ello sin importar lo estruendoso de la carcajada.

En su libro El ambiente emocional para el aprendizaje, Ginnot (1985) confirma la trascendencia de las sonrisas docentes. La siguiente cita enfatiza que la falta de sonrisas de los profesores es señal de que no se sienten a gusto o no les agrada su trabajo:

Cuando volví a casa, me sentía anonadada. En mi mente se agolpaban toda clase de ideas e imágenes. Nadie había sonreído durante todo el día, no vi una sola sonrisa. Ni un solo maestro había mostrado gusto por su trabajo... (p.66)

Las maestras percibidas como sonrientes por los alumnos muestran satisfacción por su labor, independientemente de que rían de formas distintas. Veamos, en este sentido, algunas risas que los entrevistados consideraron chistosas. 
Risas graciosas, chistosas...

Graciosa es una palabra empleada para designar que alguien o algo está dotado(a) de gracia y agrado. Generalmente se maneja como sinónimo de chistoso, sin embargo, este último término aduce más a que algo es ocurrente, chusco y hasta humorístico. Ese es el sentido que los alumnos entrevistados le dan a algunas risas de sus profesores que lograron que toda la clase riera.

Poyatos (1994) afirma que la risa se califica por la anatomía corporal y facial, y si un profesor es de cuerpo obeso, al reír puede presentar actividades recurrentes como tos, atragantamiento, sudor, enrojecimiento facial, derramamiento de lágrimas... Es el caso del maestro $\mathrm{H}$ de Pedagogía y de la maestra B de Idiomas:

' $\mathrm{H}$ ' está gordito, entonces al contar sus historias o cuando da la clase y se acuerda de algo, ja ja ja, se ríe tanto que termina haciendo que todos nos riamos. Casi se ahoga, la cara se le pone roja y le da tos. De suerte que lleva sus pastillas de miel... (Est. 6 de Pedagogía)

Ella, la maestra 'B', es gringa, gorda, muy blanca, entonces cuando se ríe con ganas, la cara se le pone roja roja y hasta nos escupe por tanta risa hasta con lágrimas ja ja ja y nosotros nos morimos de risa por su forma de reír y ya no oímos lo que dice porque su carcajada no la deja hablar. (Est. 4 de Idio)

Como puede verse, en estos casos, los alumnos terminan riendo más de la prolongada, profunda y peculiar risa de los profesores que de lo que dicen. Al respecto, los entrevistados de Pedagogía admiten reírse más de la risa del maestro M de Pedagogía que de sus chistes:

' $\mathrm{M}$ ' es malo para contar chistes, casi nadie le entiende, ni nos enteramos cuando ya terminó el chiste... ja ja ja nos reímos porque él se ríe tan chistoso ja ja ja. Cree que nos reímos del chiste pero no, nos reímos de su risa chistosa. (Est. 2 Ped)

Es posible que dicho maestro no se haya percatado de su falta de pericia para contar chistes, justo porque provoca las risas de sus estudiantes.

Otras risas chistosas, dado que según los entrevistados se parecían a la de los personajes televisivos, fueron las siguientes:

... la maestra ' $A$ ' a veces como se ríe, no sé, tiene las risas del Chavo del Ocho, así se oye a veces la maestra. (Est. 4 Ped)

La maestra ' $R$ ', híjole se ríe igualito a Bod Esponja... quién sabe qué ha de pensar porque todo el grupo se tira de la risa cada vez que la escuchamos. (Est. 7 Idio)

Los estudiantes interpretan sentimientos y estados de ánimo de sus profesores tan solo con la risa, incluso descubren las preferencias sexuales, veamos lo que dijo un estudiante: 
La del maestro de Educación Permanente, cada vez que ríe todo el salón se ríe... porque su voz es así, como que un poquito rara, y todo el mundo el primer día que llegó fue la risa total del salón, es homosexual. Su risa lo delata que es homosexual. ( Est. 4 Ped)

Como se dijo con antelación, las risas revelan las personalidades de los docentes, y seguramente muchos profesores no han reflexionado suficientemente en torno al uso de su lenguaje verbal. A continuación, se analizan las risas no agradables para los estudiantes entrevistados:

\section{Risas desagradables}

Risas sarcásticas, burlonas, nerviosas...

Interpretar un signo por separado es arriesgado, porque siempre va acompañado de otros y uno solo no dice mucho. Los estudiantes trataron de expresar lo que a ellos les parecían risas desagradables. Naturalmente que la risa es un indicador, pero hay muchos más que, por supuesto, ameritan un análisis exhaustivo.

Entre las risas que no agradaron se encuentran las que se interpretan como risas sarcásticas y/o burlonas, veamos:

Bueno, tal vez ja ja ja (trata de imitar la risa del profesor) que, como diciendo: ‘ $¡$ ay pobre no entiende!', o sea como que cierto sarcasmo a veces... (Est. 6 Idio)

... él mira y ríe cuando pregunta, ríe como burla, con sarcasmo porque para él cualquier respuesta que le des está mal, cree que no tenemos capacidad. (Est. 3 Idio)

El sarcasmo proviene del latín sarcasmus, que literalmente significa mordedura de labios. En la comunicación escrita refiere a una burla hasta cierto punto llena de ingenio, porque el sarcástico es perspicaz para hacer uso del sarcasmo, por eso suele confundirse con la ironía; mientras que en la oral, se le reconoce comúnmente como crítica indirecta, pero expuesta de manera directa $\mathrm{y}$ tangible. Por eso, los estudiantes percibieron el uso del sarcasmo por parte de los profesores antes citados, a través de sus risas burlonas, justo en el momento en que los alumnos respondían a las preguntas. Sin palabras, manifestaron que las respuestas no solo estaban mal, sino que eran motivo para reírse burlonamente. La burla alude al engaño, el abuso de confianza, la mofa, hasta llegar a la ridiculez.

Los profesores la expresan, en efecto, con su forma de reír, veamos:

...solo cuando utilizaba a alguno de nuestros compañeros para ridiculizarlo y obtener la respuesta, se reía de los compañeros que no sabían. (Est. 5 Ped)

La de 'Mar', se reía je je je (imita la sonrisa), era una sonrisa muy burlona, ridiculizaba. (Est. 1 Ped)

El manejo del lenguaje no verbal no siempre es reflexionado. ¿Es posible, entonces, que estos 
maestros estén conscientes del uso de sus risas y sonrisas y las interpretaciones de sus receptores?

La sonrisa como signo kinésico interactúa con el lenguaje verbal. Es decir, al mismo tiempo que un maestro habla, sonríe para confirmar lo que dice. Aunque a veces en lugar de confirmar, contradice o confunde, -depende del volumen-, tono, acentuación, modalidad, matiz... de la risa.

Una sonrisa acompañada de una carcajada en el momento en que un alumno está respondiendo una pregunta puede provocar muchos sentimientos en este, el más común entre ellos, es sentirse objeto de burla.

Una vez que me preguntó y yo le respondí lo que para mí era, pues se rió tanto que me sentí humillado, y ya no quise participar más, mejor no le respondía cuando preguntaba. (Est. 1 Idio)

Comúnmente la risa se utiliza o manifiesta para expresar felicidad o ánimo, ya que, cuando algo la provoca emerge espontáneamente como señal de alegría; sin embargo, de acuerdo con esto que analizamos, es otro el uso que los profesores le dan a la risa. Así, salga espontáneamente o haya un esfuerzo por parte de los maestros, lo cierto es que la risa no es percibida por los alumnos como producto de felicidad o ánimo. Como dijimos, al reír los maestros están rechazando sin palabras las respuestas de los alumnos, lo cual es hasta cierto punto aceptable, porque pueden ser maestros exigentes; empero habría que preguntarse si esa es la mejor manera de exigir mayor implicación a los alumnos, puesto que pedagógicamente es incorrecto mofarse de los otros:

La de un maestro, su risa era burlona. Se burlaba de los compañeros que no sabía responderle a sus preguntas, y eso los cohibía en lugar de ayudarles... Obviamente, ya no quieres participar con este tipo de maestros. (Est. 2 Ped)

Como bien lo expresa el alumno 2 de Pedagogía, lejos de apoyar a los estudiantes, con este tipo de risa se les limita la espontaneidad y el deseo de expresarse. Desde la percepción del alumno, un buen maestro se caracteriza por entablar relaciones humanas armoniosas en el aula (Hernández, 2014). En ese sentido, como decía Ginott (1985), la primera cualidad que debería tener un buen maestro es la actitud y la capacidad de crear un ambiente emocional propicio para el trabajo de grupo, y ello no se logra a través del uso de los signos no verbales que inhiben o cierran los canales de comunicación.

El rostro es portador de múltiples emociones, que se denominan mezclas de afectos. (Knapp, 1999, p.236)

Las mezclas faciales suscitadas por las emociones pueden aparecer en el rostro de diferentes formas, bien el maestro levanta la ceja como expresando sorpresa, y a la vez aprieta los labios con expresión de cólera (Hernández, 2011), o encorvar los labios tratando de sonreír 
forzadamente cuando algo no lo hace feliz, pero evita hacerlo notar... Para cada emoción particular hay una zona de la cara que produce información. La zona nariz/mejilla/boca es esencial para el disgusto; para el miedo, la zona clave es la de los ojos/párpados; para la tristeza, podría ser la de las cejas/frente y ojos/párpados; para la felicidad; la zona de las mejillas/boca y la de las cejas/frente (Knapp, 1999).

De este modo, tan solo por las risas y sonrisas de sus profesores los estudiantes detectaron emociones como la inseguridad y el nerviosismo de ciertas maestras:

La sonrisa de la maestra 'C' es muy nerviosa y muy rápida... transmitía como eso, nervios. (Est. 1 Ped)

Hay muchas sonrisas de confianza, sonrisa coquetona, sonrisa de sarcasmo, sonrisa insegura, porque a veces hay sonrisas inseguras. Sí he notado de algunos maestros, sobre todo de maestras que ríen de nervios porque quizás no dominan la clase. (Est. 3 Ped)

A partir de la risa de la maestra, el estudiante 3 de Pedagogía se aventura a interpretar que dicha maestra es insegura "quizás porque no domina la clase".

Pero, por otra parte, muchas respuestas de los entrevistados, sobre todo de Idiomas, se constituían en fuertes críticas para las maestras que no reían, como la siguiente:
Es que es infeliz, nunca rió y siempre está enojada, nosotros creemos que porque no tiene marido ja ja ja. (Est. 2 Idio)

Con esta cita cerramos este artículo, modesto quizás, pero en sí un peculio reflexivo para abrir el espacio a las conclusiones y reflexiones finales.

\section{Discusiones y conclusiones}

Mucha de la reflexión teórica de la investigación se sustenta en el libro Práctica docente. Más allá de cuatro paredes, pizarrón $y$ mesabancos. Libro de interés para todo aquel comprometido con la enseñanza, porque analiza a la docencia desde una mirada compleja. Quien enseña no solo es un profesor(a) legitimado institucionalmente para hacerlo, es también una persona con derecho a errar, conmoverse, desalentarse, frustrarse.... (Hernández, 2014), es mujer u hombre, joven o no... Cumple más roles... y, especialmente, tiene una personalidad que lo hace único. Sin embargo, independientemente de su esfera personal, el profesor debe cumplir un rol determinado por la misma institución, modelos pedagógicos, exigencias sociales, etcétera.

Como vimos cuando definimos el concepto de percepción, este se halla supeditado a imposiciones socioculturales sobre lo que es adecuado o no, correcto e incorrecto; luego entonces, las formas de reír o no son visualizadas, aceptadas o rechazadas sin dificultades por los estudiantes. 
Muchas veces ellos son fuertes críticos de sus profesores sin conocer de fondo el mundo interior de estos. Aducen que una maestra no ríe porque "no está casada", pero en realidad ignoran si esa sea la razón de la ausencia de la risa. Tampoco saben qué pasa con el maestro o maestra que ríe mucho, realmente están felices o ¿qué tal si les suceda lo mismo que a Garrik, el mejor payaso del pueblo de Inglaterra? (según el poema de Juan de Dios):

Viendo a Garrik -actor de la Inglaterra, el pueblo al aplaudirle le decía: «Eres el más gracioso de la tierra y el más feliz...» Y el cómico reía. (...) Una vez, ante un médico famoso, llegóse un hombre de mirar sombrío: «Sufro -le dijo-, un mal tan espantoso como esta palidez del rostro mío». Nada me causa encanto ni atractivo; no me importan mi nombre, ni mi suerte en un eterno spleen muriendo vivo, y es mi única ilusión, la de la muerte». -Viajad y os distraeréis. ¡Tanto he viajado! -Las lecturas buscad. -¡Tanto he leído! -Que os ame una mujer. -iSi soy


nacido!-¿Pobre seréis quizá? -Tengo riquezas -¿De lisonjas gustáis? -¡Tantas escucho!(...) - ¿Me deja -agrega el médico- perplejo vuestro mal y no debo acobardaros; Tomad hoy por receta este consejo: solo viendo a Garrik, podréis curaros. -¿A Garrik? -Sí, a Garrik... La más remisa y austera sociedad le busca ansiosa; todo aquel que lo ve, muere de risa: tiene una gracia artística asombrosa. $-i \mathrm{Y}$ a mí, me hará reír? -¡Ah!, sí, os lo juro, él sí y nadie más que él; mas... ¿qué os inquieta? -Así -dijo el enfermo- no me curo; ¡Yo soy Garrik!... Cambiadme la receta...
No todo el que ríe está feliz. Los alumnos desean que sus profesores rían en la clase porque de acuerdo con sus percepciones, eso genera un ambiente de confianza, en especial para las participaciones espontáneas, pero, ¿hasta qué punto se estaría forzando a un docente a hacerlo cuando no le nace o quiere reír? Por supuesto que lo ideal es que hubiera risas francas y naturales.

El tema de las risas del profesorado, en apariencia simple, genera una serie de reflexiones en torno a la práctica y formación docente, incluso desde una mirada transdisciplinaria. $\mathrm{Si}$ quisiéramos comprender la ausencia o presencia de risas y las formas en que este ríe y sus efectos, necesariamente tendríamos que adentrarnos en el mundo interior de los enseñantes (Abraham, 1987), desde varias aristas: la salud, vocación, estabilidad económica, laboral y emocional, etc., y no limitarnos a lo que marcan los nuevos modelos educativos en torno al deber ser del maestro. En efecto, se requiere de un saber profundo del profesorado así como del contexto que lo rodea para comprenderlo, pero también es indispensable repensar a la formación docente en tanto espacio que abra el horizonte analítico del trascendental papel que el profesor como educador tiene en la formación de los educandos.

No se espera que el maestro sea una especie de robot que controla sus emociones, pero sí que reflexione sobre su papel como enseñante y profesional con ética. Todo profesor es responsable de abrir o cerrar los canales de comunicación, y una simple sonrisa puede hacer la diferencia. 
Finalmente, los resultados nos permiten esbozar algunas sugerencias para las instancias en donde se realizó la indagación. Si bien el profesor universitario cuenta con autonomía para dar su clase, convendría que los formadores de docentes hicieran visitas directas a las aulas para que los cursos que proporciona la universidad realicen mejoras necesarias a partir de las situaciones vividas por los maestros y estudiantes y, así, elucidar estos eventos reveladores y trascendentales de las interacciones didácticas.

En este marco, sería importante la creación de seminarios para que los docentes reflexionen sobre su actuar y proceder, en especial en el manejo de su lenguaje corporal y facial. Mas no para que se programen en su control, sino para que se visualicen como actores protagónicos en la apertura y cierre de canales de comunicación. Comunicación que es indispensable en el aula para que se propicien aprendizajes significativos de manera constructivista.

Tales cursos también debieran servir para que los docentes exterioricen eventos de índole personal que los hacen manifestarse de determinada manera en las aulas; en síntesis, una forma de espacio catártico en pro de la interacción didáctica y todo lo que esta implica.

\section{Referencias}

Abraham, A. (1986). El enseñante es también una persona: conflictos y tensiones en el trabajo docente. Barcelona: Gedisa.
Abraham, A. (1987). El mundo interior de los enseñantes. España: Paidós.

Birdwhistell, R. (1966) Kinesics and contest. Essays on Body Motion Communication. Pennsylvania: University of Pennsylvania Press.

Bourdieu, P. (1999). La dominación masculina. Barcelona: Anagrama.

Davis, F. (2000) La comunicación no verbal. Madrid: Alianza.

De Dios, J. (1879). Reír llorando. Tomado de http://www.poemas-del-alma.com/juande-dios-peza-reir-llorando

Delamont, S. (1986). La interacción didáctica. Madrid: Kapeluz.

Durkheim, E. (1978). Educación y sociología. Buenos Aires: Tauro.

Fierro, C., Fortoul, B. \& Rosas, L. (1999). Transformando la Práctica Docente. Una propuesta basada en la investigación-acción. México: Paidós.

Gage, N. (1978). La base cientifica del arte de la enseñanza. Nueva York, EUA: Prensa de Teachers Collage.

García, M. \& Estebaranz, A. (1992). Estrategias de formación centradas en el contenido $y$ en el formador. Estrategias deductivas. Argentina: Sevilla.

Ginnot, W. (1985). Maestro alumno. El ambiente emocional para el aprendizaje. México: Pax.

Hernández, G. (2011). Miradas docentes. Revista Docencia e Investigación, (21), 71-87.

Hernández Méndez, G. (2012). Práctica docente. Más allá de cuatro paredes, pizarrón y mesabancos. México: Arana. 
Hernández Méndez, G. (2014). La efectividad de la enseñanza y los rasgos personales de los docentes. Percepciones de estudiantes universitarios. México: Universidad Veracruzana.

Knapp, M. (1999). La comunicación no verbal. México: Paidós.

Mann, L. (1972). Elementos de psicología social. México: Limusa.

Poyatos, F. (1994). La comunicación no verbal. Biblioteca Española de Lingüística y Filología. Madrid: Istmo.
Ruiz Olabuénaga, J. (2003). Metodología de la investigación cualitativa. Bilbao: Universidad de Deusto.

Stubb, M. \& Delamont (1978). Las relaciones profesor-alumno. Barcelona: Oikos-tau.

Villa, A. (1988). Perspectivas de la función docente. Madrid: Narcea.

Wildeblood, J. \& Bryson, P. (1965). The polite world a guide to English manner and deparment from the thirteenth to the nineteenth centuary. London: Oxford University. 